\title{
A COMISSÃO NACIONAL DO LIVRO DIDÁTICO APÓS 1945 E OS LIVROS DE MATEMÁTICA APROVADOS PARA USO NO ENSINO SECUNDÁRIO
}

\author{
Bruno Alves Dassie ${ }^{1}$ \\ Universidade Federal Fluminense - UFF
}

\section{RESUMO}

A Comissão Nacional do Livro Didático foi instituída pelo Governo Federal em 1938. Algumas pesquisas analisaram os trabalhos dessa comissão, principalmente, na gestão de Gustavo Capanema (1934-1945) no Ministério da Educação e Saúde. Essas pesquisas apontam, entre outras questões relacionadas com o funcionamento da comissão, a problemática da divulgação das listas dos livros aprovados. Desse modo, o objetivo deste trabalho é apresentar a localização das listas que foram publicadas em Diário Oficial da União entre os anos de 1947 e 1961. Em particular, ao final, iremos dar destaque aos livros de matemática que foram aprovados para uso no ensino secundário.

Palavras-chave: Comissão Nacional do Livro Didático; história da Educação Matemática; livros didáticos.

\section{THE TEXTBOOK NATIONAL COMMISSION AFTER 1945 AND THE MATHEMATICS TEXTBOOKS APPROVED FOR THE SECONDARY SCHOOLS}

\begin{abstract}
The Textbook National Commission was constituted in 1938 by Federal government. Some researchers have studied the activities of this commission, particularly for the period in which Gustavo Capanema was Minister for Education (1934-1945). A particular question so far investigated was how the lists of the approved textbooks were published. The aim of the present research was to find all the lists for the period 1947-1961, after Capanema's had left the Ministry. At the end, we make comments on the mathematics textbooks approved for the secondary schools.
\end{abstract}

Keywords: Textbook National Commission; history of mathematics education; textbooks.

\section{Introdução}

Nas últimas décadas há um crescente interesse no uso do livro didático como objeto de pesquisa em suas inúmeras vertentes. Segundo Bittencourt (2004, p. 471), os levantamentos bibliográficos "mostram que houve uma tendência, iniciada na década de 1960, de se analisarem os conteúdos dos livros escolares privilegiando a denúncia do caráter ideológico dos textos". E,

A partir dos anos 1980, muitos dos problemas relacionados ao conteúdo ou ao processo de produção e uso do livro didático por professores e alunos passaram a ser analisados em uma perspectiva histórica, constituindo-se tais análises em uma das vertentes mais importantes desse campo de investigação (BITTENCOURT, 2004, p. 472).

Por outro lado, em paralelo "às análises sobre os conteúdos, foram sendo acrescidas outras temáticas, notadamente as relações entre as políticas públicas e a produção didática, 
evidenciando o papel do Estado nas normatizações e controle da produção" (BITTENCOURT, 2004, p. 471).

Nesse sentido, destacam-se as análises de Oliveira, Guimarães e Bomény, (1984) e Freitag, Costa e Motta (1987) ${ }^{2}$. Nesses trabalhos, a relação entre livro didático e as políticas públicas ultrapassa a apresentação das normatizações das propostas instituídas a partir da década de 1930, com a criação da Comissão Nacional do Livro Didático - CNLD -, como iniciativa de legislar e controlar o livro didático no Brasil. As duas pesquisas citadas se estendem até a década de 1980, com discussões sobre aspectos que passam a figurar no cenário das ações do Estado para com o livro didático, como por exemplo, a compra e a distribuição gratuita dessas obras e as implicações em seus usos na escola. Sendo assim,

A importância do livro didático não se restringe aos seus aspectos pedagógicos e às suas possíveis influencias na aprendizagem e no desempenho dos alunos. O "mercado" criado em torno do livro didático faz dele importante mercadoria econômica, cujos custos muito influem na possibilidade de acesso, a ele, de expressivo contingente da população escolarizada. O livro didático também é importante por seu aspecto político e cultural, na medida em que reproduz e representa os valores da sociedade em relação à sua visão de ciência, da história, da interpretação dos fatos e do próprio processo de transmissão do conhecimento (OLIVEIRA; GUIMARÃES; BOMÉNY, 1984, p. 11).

Cabe ainda destacar, que os trabalhos de Oliveira, Guimarães e Bomény (1984) e Freitag, Costa e Motta (1987) nos ajudam a compreender a relação entre o livro didático e as políticas públicas, ou o livro didático como política pública, numa perspectiva histórica ou presente, pois nos apresentam asserções que favorecem o entendimento das ações do Estado relativas ao livro didático no campo educacional.

Ao tratarmos do livro didático do ângulo político, partimos de duas constatações [...] como se fossem premissas. A primeira refere-se ao fato de que a política do livro didático [...] é praticamente idêntica com a política estatal do livro didático. A segunda relembra o fato óbvio, que por isso mesmo não se pode esquecer, a necessidade da contextualização da política do livro didático. Essa política não é senão um aspecto particular da política educacional global, que por sua vez, se insere nas mudanças estruturais político-econômicas da sociedade brasileira como um todo (FREITAG; COSTA; MOTTA, 1987, p. 13).

Mais recentemente as pesquisas sobre livro didático, sob a ótica das políticas públicas, dedicam-se ao Programa Nacional do Livro Didático - PNLD - e as diversas variáveis imbricadas nesse processo. Cassiano (2007), por exemplo, analisa o mercado editorial brasileiro, de 1985 a 1987, tendo como marco a criação do PNLD. Zúñiga (2007) analisa os impactos desse programa nos livros didáticos de matemática de $6^{\circ}$ ao $9^{\circ}$ ano, entre o PNLD 1999 e o PNLD 2005.

Tomando como objeto de análise as origens dos processos de avaliação de livros didáticos no Brasil, além da pesquisa de Oliveira, Guimarães e Bomény (1984), Soares e Rocha (2005) e Ferreira (2008) apresentam detalhes sobre a criação e o funcionamento da CNLD, em particular, na administração de Gustavo Capanema no Ministério da Educação e Saúde, entre os anos de 1934 e 1945. Tais produções tomam como base documental o 
acervo do referido Ministro, localizado no Centro de Pesquisa e Documentação de História Contemporânea do Brasil - CPDOC -, da Fundação Getúlio Vargas, no Rio de Janeiro.

Soares e Rocha (2005) elegem o recorte a partir do dossiê próprio da $\mathrm{CNLD}^{3}$, com a análise do decreto de criação e dos de funcionamento. Além disso, apresentam de dados sobre a organização das subcomissões e seus respectivos membros e detalhes sobre os critérios que deveriam ser considerados na avaliação das obras. Ferreira (2008), devido à natureza da pesquisa, precede a análise da criação e funcionamento da CNLD com um detalhamento da estrutura administrativa do Ministério de Educação e Saúde, situando, de forma ampla, o livro didático na política educacional a partir da década 1930.

É destaque nessas pesquisas o relato das dificuldades de execução plena do trabalho por parte da CNLD. Essa comissão foi criada em 1938 pelo Decreto-lei n. 1006, de 30 de dezembro, que estabeleceu as condições de produção, importação e utilização do livro didático, considerado como compêndio ou livro de leitura de classe. A CNLD foi instituída pelo art. $9^{\circ}$ da referida lei e deveria ser composta por sete membros, "escolhidos dentre pessoas de notório preparo pedagógico e reconhecido valor moral". As atribuições previstas para CNLD eram: a) examinar os livros didáticos apresentados para avaliação e proferir julgamento favorável ou contrário à autorização de seu uso; b) estimular a produção e orientar a importação de livros didáticos; c) indicar os livros didáticos estrangeiros de notável valor, que merecessem ser traduzidos pelos poderes públicos, bem como sugerir-lhes a abertura de concurso para a produção de determinadas espécies de livros didáticos de sensível necessidade; d) promover, periodicamente, a organização de exposições nacionais dos livros didáticos com uso autorizado na forma desta lei. (Art. $10^{\circ}$ ).

Nas palavras de Oliveira, Guimarães e Bomény (1984, p. 39), as dificuldades na execução da lei ocorrem devido à "mecânica do funcionamento pedagógico-burocrático", imposta pelas atribuições pretenciosas do Art. $10^{\circ}$ citado acima. Segundo Ferreira (2008),

As dificuldades encontradas por Gustavo Capanema para compor de modo satisfatório a Comissão Nacional do Livro Didático são perceptíveis no número de rascunhos, no qual os nomes foram constantemente trocados e fica evidente a dificuldade do Ministro em manter o número de integrantes segundo o que fora estabelecido pela lei (FERREIRA, 2008, p. 58).

As dificuldades estiveram presentes ao longo de todo o período da gestão de Gustavo Capanema. Nesse sentido, diversos acertos foram feitos para tentar sanar os problemas de execução do decreto pela via da CNLD.

O aspecto interessante de todo o processo de implementação da política do livro didático talvez seja o que se refere ao movimento de paulatina redução da ambição original, com sucessivas medidas adicionais de simplificação. Já em 29 de março de 1939, o presidente da República assina o Decreto-lei n. 1.177 que amplia para dezessete o número de membros da Comissão Nacional do Livro Didático. Essa medida de urgência já atentava para o fato de que a partir de $1^{\circ}$ de janeiro de 1940 , o uso dos livros didáticos estaria dependente da autorização do Ministro Capanema, o que exigiria da CNLD, no primeiro ano de funcionamento, um desempenho de excepcional intensidade. Essa expectativa, todavia, viu-se completamente frustrada, já que o ano de 1939 transcorrera sem que fosse sequer instalada a Comissão (OLIVEIRA; GUIMARÃES; BOMÉNY, 1984, p. 39). 
Além do aumento do número de membros, a CNLD foi desdobrada em nove seções ${ }^{4}$. No entanto, mesmo com esses ajustes, "até maio de 1941, quatro meses após a instalação da CNLD, do total de 1.986 livros didáticos encaminhados para exame, menos que $10 \%$ haviam sido analisados". (FERREIRA, 2008, p. 78). Outras medidas foram tomadas, como, por exemplo, a relatada por Soares e Rocha (2005):

Em uma sessão da CNLD, realizada em 11 de dezembro de 1941, Gustavo Capanema se pronunciou em relação à "necessidade de solução urgente para a questão do livro didático, acentuando que esse caráter de urgência obriga o governo a adotar medidas que, se não resolvem de um modo perfeito e acabado a questão, atendem satisfatoriamente às linhas gerais do problema, permitindo soluções imediatas”. Uma dessas medidas é a supressão da seção de Redação sem, entretanto, deixar de cobrar dos autores o cuidado com a língua oficial e com a linguagem empregada (SOARES; ROCHA, 2005, p. 103).

Todas as complexidades do sistema criado inquietaram o mercado editorial. Oliveira, Guimarães e Bomény (1984, p. 41) consideram que "da lista dos afetados por todo o processo desde o início, as editoras ocupam um lugar destacado". Segundo Soares e Rocha (2005, p. 104), "Diversas editoras [...] além do próprio Sindicato Nacional das Empresas Editoras de Livros e Publicações Culturais, manifestaram-se contra algumas decisões tomadas pela CNLD e por Capanema". E mais,

Em uma carta ao ministro, os editores comunicam que, devido às alterações feitas no currículo do curso secundário ${ }^{5}$, e na dúvida se os livros receberiam ou não autorização de uso pela CNLD, considerando o atraso dos trabalhos de avaliação, resolveram paralisar todo o trabalho de edição e reedição dos livros destinados a esse segmento, a fim de se evitar maiores prejuízos. Além disso, as editoras pedem o adiamento da publicação da relação dos livros de uso autorizado, para janeiro de 1943. Em outra carta, as editoras lembram que a CNLD "vem fazendo publicar apenas o número do processo relativo ao livro recusado" e salientam o fato de que a "revogação desta praxe, para tornar pública uma lista detalhada de obras não aceitas pela Comissão, nada acrescentaria à defesa do ensino; em compensação, acarretaria inúteis vexames, senão prejuízos irreparáveis, a numerosos autores e editores" (SOARES; ROCHA, 2005, p. 104-105).

Observa-se então que a publicação das listas de livros aprovados é o centro das dificuldades enfrentadas publicamente pela CNLD no decorrer da gestão de Gustavo Capanema.

As discussões sobre a divulgação das listas prosseguem e o ano de 1943, pelo que foi apontado em duas das pesquisas citadas (SOARES; ROCHA, 2005; FERREIRA, 2008), foi o marco para a publicação das mesmas. No entanto, o problema persistiu. Em 1944, como relatado por Oliveira, Guimarães e Bomény (1984, p. 42), Gustavo Capanema enviou "um projeto de decreto-lei à Presidência da República em cuja apresentação" mencionou "a precariedade do cumprimento da legislação aprovada em 1938":

A vigente legislação relativa ao livro didático, decretada em 1938 por V.Excia., contém as disposições necessárias à obra, que se torna cada dia mais imperiosa, de tornar a literatura didática de nosso país mais adequada aos seus fins educativos. 
Grande parte dessa literatura, produção que é de professores doutos e experimentados, possui grande valor. Outra parte, porém, já pela deficiência ou erro da exposição, já pela falta de observância dos preceitos essenciais de uma conveniente pedagogia, não está à altura do papel que é chamada a desempenhar na vida escolar do país.

No momento que se renova e amplia a legislação pedagógica do país, mais necessária se torna a revisão da nossa literatura didática.

Para empreender esse trabalho se afigura necessário que entre a funcionar a Comissão Nacional do Livro Didático, instituída pelo Decreto-lei n. 1.006 , de 30 de dezembro de 1938 (CAPANEMA apud SOARES; ROCHA, 2005, p. 106-107) ${ }^{6}$.

Este projeto "pretendia tornar possível e em condições satisfatórias de eficiência, o funcionamento da Comissão". Além disso, "a data a ser fixada para que a adoção dos livros obedecesse à regulamentação seria novamente marcada pelo Ministro da Educação". Mas, "é possível que ao final da gestão Capanema [...] não se tivesse, ainda, assistido aos resultados esperados e tão anunciados desde 1938" (OLIVEIRA; GUIMARÃES; BOMÉNY, 1984, p. 42-43). De fato, durante a gestão de Gustavo Capanema, no Ministério da Educação e Saúde, nenhuma lista foi publicada, o que confirma a hipótese de Soares e Rocha (2005):

Os vários documentos relativos ao funcionamento da Comissão Nacional do Livro Didático sugerem que, mesmo sem que a tal lista fosse publicada como manda o Decreto n..$^{\circ}$ 1.006, muitos livros chegaram a ser avaliados e excluídos. Entretanto, não há no Arquivo Gustavo Capanema - pelo menos nas pastas referentes ao tema "Livro Didático" - nenhum parecer dado pela Comissão e nenhuma relação provisória de quais livros foram submetidos, avaliados ou excluídos. Os únicos títulos sobre os quais se pode ter certeza que passaram pela avaliação são aqueles escritos pelos membros da CNLD, os quais provavelmente foram autorizados para uso (SOARES; ROCHA, 2005, p. 104).

Assim, o objetivo deste artigo é tratar de detalhes sobre o funcionamento da CNLD após 1945 e, em particular, apresentar a localização das listas de livros aprovados para uso nas instituições de ensino, bem como tecer considerações sobre os livros de matemática aprovados para uso na escola secundária. As buscas foram feitas no Diário Oficial da União, pois como previsto no decreto de criação da comissão, Art. $18^{\circ}$, o Ministério da Educação publicaria "no 'Diário Oficial', em janeiro de cada ano, a relação completa dos livros didáticos de uso autorizado, agrupados segundo os graus e ramos do ensino, e apresentados, em cada grupo, pela ordem alfabética dos autores" (BRASIL, 1938).

\section{A Comissão Nacional do Livro Didático após a gestão de Gustavo Capanema}

Após a gestão de Gustavo Capanema dada no fim do Estado Novo, o Governo Federal reafirma sua intenção de avaliar livros didáticos, apesar das dificuldades enfrentadas na execução das leis que estavam sendo promulgadas a partir de 1938 que tratavam dessa temática. A primeira ação nesse sentido foi feita com a publicação do Decreto-lei n. 8460 do dia 26 de dezembro de 1945 ${ }^{7}$. Essa lei, segundo sua ementa, consolidou a legislação sobre as condições de produção, importação e utilização do livro didático, e estava dividida em cinco capítulos, a saber: Da elaboração e utilização do livro didático, Da Comissão Nacional do Livro Didático, Do processo de autorização do livro 
didático, Das causas que impedem a autorização do livro didático e Disposições gerais e transitórias.

Eram considerados livros didáticos os compêndios (livros que exponham, total ou parcialmente, a matéria das disciplinas escolares) e os livros de leitura (livros usados para leitura dos alunos em aula) (Art. $1^{\circ}$ ). Os livros didáticos só poderiam ser adotados no ensino das escolas primárias, secundárias, normais e profissionais se fossem avaliados e aprovados pela comissão (Art. $3^{\circ}$ ). Diferente do Decreto-lei 1006, de 1938, este trecho da lei não estipulou uma data fixa para dar inicio a essa determinação. Essa data seria determinada pelo Ministério da Educação ${ }^{8}$.

A CNLD deveria ser composta por quinze membros "escolhidos dentre pessoas de notório preparo pedagógico e reconhecido valor moral" (Art. $11^{\circ}$ ). Segundo o Art. $12^{\circ}$, as atribuições desta comissão seriam: examinar os livros didáticos apresentados, e proferir julgamento favorável ou contrário à autorização de seu uso; estimular a produção e orientar a importação de livros didáticos; indicar os livros didáticos estrangeiros de notável valor, que merecessem ser traduzidos e editados pelos poderes públicos, bem como sugerir-lhes a abertura de concurso para a produção de determinadas espécies de livros didáticos de sensível necessidade e ainda não existentes no país.

Em relação do processo de avaliação dos livros, a CNLD deveria emitir parecer favorável, ou não, mencionando os "motivos precisos da decisão". Seria possível também "indicar modificações ou correções a serem feitas no texto da obra examinada" como condicionamento para sua aprovação (Art. $18^{\circ}$ ). As reedições dos livros autorizados poderiam ser feitas desde que não incluíssem "importantes adições ou alterações" (Art. $21^{\circ}$ ). Os livros de autoria de membros da própria comissão seriam avaliados por pareceristas externos (Art. 25\%).

Quanto à divulgação das listas, segundo o Art. 23, o Ministério da Educação e Saúde seria o órgão responsável por esta publicação e isso ocorreria semestralmente. Além disso, o Art. $24^{\circ}$ determinava que os livros didáticos de uso autorizado, deveriam conter na capa, impresso diretamente ou por meio de etiqueta, os seguintes dizeres: "Livro de uso autorizado pelo Ministério da Educação e Saúde". Os critérios de exclusão da obra estavam listados nos Art. $26^{\circ}$ a $30^{\circ}$. Prevalecem, no Art. $26^{\circ}$, os impedimentos "relacionados à questão político-ideológica" (OLIVEIRA; GUIMARÃES; BOMÉNY, 1984, p. 35) do Decreto-lei n. 1006, de 30 de dezembro de 1938:

Art. 26. Não poderá ser autorizado o uso do livro didático:

a) que atente, de qualquer forma, contra a unidade, a independência ou a honra nacional;

b) que contenha, de modo explícito ou implícito, pregação ideológica ou indicação da violência contra o regime democrático;

c) que envolva qualquer ofensa às autoridades constituídas, às forças armadas, ou às demais instituições nacionais;

d) que despreze ou escureça as tradições nacionais, ou tente deslustrar as figuras dos que se bateram ou se sacrificaram pela pátria;

e) que encerre qualquer afirmação ou sugestão, que induza o pessimismo quanto ao valor e ao destino do povo brasileiro:

f) que inspire o sentimento da superioridade ou inferioridade do homem de uma região do país, com relação ao das demais regiões;

g) que incite ódio contra as raças e nações estrangeiras;

h) que desperte ou alimente a oposição e a luta entre as classes sociais e raças;

i) que procure negar ou destruir o sentimento religioso, ou envolva combate a qualquer confissão religiosa. 
j) que atente contra a família, ou pregue ou insinue conta a indissolubilidade dos vínculos conjugais;

k) que inspire o desamor à virtude, induza o sentimento da inutilidade ou desnecessidade do esforço individual, ou combata as legítimas prerrogativas da personalidade humana (BRASIL, 1945).

Os critérios de ordem didática, limitados a três, estavam listados no Art. $27^{\circ}$. Seria "negada autorização de uso ao livro didático" que estivesse "escrito em linguagem defeituosa, quer pela incorreção gramatical, quer pelo inconveniente ou abusivo emprego de termos ou expressões regionais ou de gíria, quer pela obscuridade do estilo"; que apresentasse "o assunto com erros de natureza científica ou técnica"; e que estivesse "redigido de maneira inadequada, pela violação dos preceitos fundamentais da pedagogia ou pela inobservância das normas didáticas oficialmente adotadas" ou que estivesse "impresso em desacordo com os preceitos essenciais da higiene da visão". (Art. 26 ). Outros critérios relacionavam-se com a identificação da autoria (o nome do autor deveria ser impresso por extenso); declaração do preço de venda; uso da língua materna no caso dos livros destinados ao ensino primário; manutenção da ortografia corrente. (Art. $27^{\circ}$, itens $d$ e $e$; Art. $28^{\circ}$ e $29^{\circ}$ ).

Após a autorização do uso do livro didático o seu preço de venda não poderia ser alterado sem prévia licença da comissão (Art. $33^{\circ}$ ) e os livros com falsas declarações de uso autorizado seriam apreendidos (Art. $39^{\circ}$ ).

Este decreto é assinado pelo então Presidente José Linhares e pelo Ministro da Educação e Saúde, Raul Leitão da Cunha ${ }^{9}$.

É possível observar, a partir de uma comparação com o Decreto-lei n. 1006, de 30 de dezembro de 1938, que essa lei corrobora com o projeto elaborado na gestão Capanema. Mas, apesar desse decreto reafirmar uma política centralizadora, encontra-se na gestão de Clemente Mariani no Ministério da Educação e Saúde ${ }^{10}$ ações que tentam sanar as dificuldades enfrentadas no processo que tiveram origem no "momento político no qual foi gerado o projeto do livro didático" (OLIVEIRA; GUIMARÃES; BOMÉNY, 1984, p. 45). Cabe observar, que a partir de 1946, uma nova Carta Constitucional entre em vigor e o "país movimenta-se politicamente, no pós-45, [...] já em outro cenário" (OLIVEIRA; GUIMARÃES; BOMÉNY, 1984, p. 43).

Clemente Mariani, em entrevista sobre "as instruções especiais baixadas [...] a fim de que se cumpram [...] as determinações legais referentes à autorização do uso de livros didáticos nas escolas primárias, secundárias, profissionais e normais" (O LIVRO..., 1947, p. 2), concedida ao jornal Folha da Manhã, publicada em 11 de setembro de 1947, apresenta esclarecimentos sobre o acúmulo de trabalho da CNLD e as suas consequências e a possibilidade de alteração na lei vigente, em especial, sobre os possíveis recursos por parte dos autores e editoras ${ }^{11}$.

\section{O LIVRO DIDATICO NAS ESCOLAS PRIMARIAS, SECUNDARIAS, PROFISSIONAIS E NORMAIS E possivel a modificaçăa da legislaçăo vigente sobre 0 assunto, declara 0 ministro Clemente Mariani}

Folha da Manhã, 11-09-1947, Primeiro Caderno, p. $2^{12}$. 
Sobre o excesso de trabalho, Mariani declara que:

O exame de livros e material de uso escolar é prática habitual na maioria dos países, e em países democráticos como o nosso, deverá exercer-se especialmente com o propósito de cooperação técnica, entre autores e editores, de uma parte e os órgãos de administração escolar, de outra. A experiência realizada por este Ministério, por intermédio da Comissão Nacional do Livro Didático, tem evidenciado a utilidade dessa prática, na elevação constante do padrão científico e pedagógico de nossas obras didáticas.

Inicialmente, encontrou a Comissão trabalho dos mais árduos. Bastará dizer que cerca de dois mil livros didáticos foram apresentados no seu exame e parecer. Desses, 1168 lograram autorização de uso, sem qualquer objeção, e 230, em termos condicionais, tendo sido rejeitados 575 (O LIVRO..., 1947, p. 2).

A demora na publicação das listas de livros de uso autorizado é justificada pelo Ministro. Segundo ele,

A publicação dos resultados que a Comissão fosse desde logo apurando, a cada ano, depois de exame apenas de uma parte das obras correntes, não teria sido medida de prudência e de justiça, pois daria preferencia acidental a certos autores e editores, com prejuízo aos demais.

Agora, porém, examinada como está, praticamente, a totalidade das obras, a lei deverá ser cumprida, na parte de "autorização de uso" nas escolas. Recomendei, por isso, que se fizesse a publicação da lista das obras que hajam logrado parecer favorável, e entre as quais os professores escolherão livremente as que tiverem de adotar, no próximo ano letivo. A publicação deverá ser feita desde já, segundo os pareceres da Comissão, ano por ano, desde que iniciou os seus trabalhos em 1941 (O LIVRO..., 1947, p. 2).

A discrepância entre as edições avaliadas e as possíveis edições em circulação no momento da publicação das listas, cerca de nove anos após a criação da CNLD e inscrição das obras, também foi um tema abordado pelo Ministro. Segundo ele, os livros que não tivessem "matéria a ser atualizada quanto à vida administrativa e ao regime constitucional vigente" poderiam imprimir o número de registro e a menção "de uso autorizado", como determinava o Art. $24^{\circ}$, do Decreto-lei n. 8460, de 26 de dezembro de 1945. Os livros que contrariassem este critério deveriam ser reeditados, mas segundo ele, não eram em grande quantidade. Enfim, Clemente Mariani, ao final deste tema, reafirma o "outro cenário" político citado por Oliveira, Guimarães e Bomény (1984, p. 43). Segundo o Ministro,

A referida atualização não exclui, certamente, a menção de fatos históricos da vida nacional ou mundial. Mas não se poderá permitir que crianças e jovens tenham em mãos informações errôneas sobre a vida constitucional do país, ou com a apologia de princípios ou doutrinas políticas que não se enquadrem no espírito constitucional vigente, que é democrático (O LIVRO..., 1947, p. 2). 
As "instruções especiais" que são citadas na introdução da reportagem se referem à Portaria n. 363 de 31 de julho de $1947^{13}$. Esta portaria dispõe sobre a aprovação de livros didáticos e é composta por apenas um parágrafo, como dado a seguir:

O Ministério da Educação e Saúde resolve determinar à Comissão Nacional do Livro Didático que faça publicar, até 31 de dezembro do corrente ano, a relação de livros aprovados, ficando estabelecido que somente tais livros, e os que vierem a ser aprovados posteriormente antes, porém, de iniciado o ano letivo - poderão ser usados para o ensino secundário e primário, no território nacional, a partir do ano de 1948.

Rio de Janeiro, 31 de julho de 1947

Clemente Mariani (BRASIL, 1947a).

E é exatamente após essa portaria que as primeiras listas de livros aprovados ou aprovados condicionalmente foram publicadas. Mais especificamente, no mês de setembro de 1947.

\section{As listas localizadas e os livros de matemática aprovados para uso no ensino secundário}

As listas com os livros aprovados ou aprovados condicionalmente foram localizadas no Diário Oficial da União entre os anos de 1947 e $1961^{14}$. Em sua maioria, tais listas são precedidas de um pequeno texto que retoma a legislação de 1945 e algumas particularidades, como pode ser visto a seguir no caso da primeira lista divulgada pela CNLD:

Para conhecimento dos interessados, publica-se, a seguir, a lista parcial n. ${ }^{\circ} 1$ dos livros didáticos julgados como de uso autorizado, por esta Comissão, e os quais, com os das demais listas, a serem publicadas, serão aqueles que poderão ser adotados nas escolas primárias, secundárias, normais e profissionais, no próximo ano letivo de 1948, na conformidade do Decreto lei n. ${ }^{\circ} 8.460$ de 26 de dezembro de 1945.

Em relação aos livros que contenham matéria referente á organização administrativa e política do país, fica esclarecido que, para que possam ter uso autorizado nas escolas, deverão atualizar essa matéria, na conformidade dos princípios constitucionais vigentes, só podendo, pois, em novas edições, assim corrigidos, apresentar o número de registro, desta Comissão, e o dístico de "Livro de uso autorizado pelo Ministério da Educação e Saúde".

Depois de publicadas as listas parciais que resumem o trabalho desta Comissão, ano por ano, será feita a publicação de todos os livros didáticos de uso autorizado, numa só relação.

As listas continham as seguintes informações sobre o livro analisado: nome do autor; título do livro; série correspondente (em alguns casos); número da edição (em alguns casos); registro do livro na CNLD; número do processo ${ }^{15}$; e preço autorizado ${ }^{16}$. Além disso, cabe observar que cada lista era separada em categorias/disciplinas e nível de ensino. Um aspecto a ser destacado é a ausência de informações sobre as editoras responsáveis por cada obra. A seguir encontra-se uma tabela com a denominação original de cada lista localizada e a data de publicação no Diário Oficial da União ${ }^{17}$. 


\begin{tabular}{|l|c|l|c|}
\hline \multicolumn{5}{|c|}{ Listas localizadas } \\
\hline \multicolumn{1}{|c|}{ Denominação } & Data da Publicação & \multicolumn{1}{c|}{ Denominação } & Data da Publicação \\
\hline Lista Parcial n.1* & $24-09-1947$ & Lista Parcial n.12 & $21-01-1954$ \\
\hline $\begin{array}{l}\text { Lista Parcial } \\
\text { Condicional n.1* }\end{array}$ & $10-10-1947$ & Lista Parcial n.13 & $13-07-1954$ \\
\hline Lista Parcial n.2* & $27-10-1947$ & Lista Parcial n.14 & $21-01-1955$ \\
\hline $\begin{array}{l}\text { Lista Parcial } \\
\text { Condicional n.2* }\end{array}$ & $06-11-1947$ & Lista Parcial n.16 & $12-01-1956$ \\
\hline Lista Parcial n.3* & $24-11-1947$ & Lista Parcial n.15 & $25-01-1956$ \\
\hline $\begin{array}{l}\text { Lista Parcial } \\
\text { Condicional n.3* }\end{array}$ & $02-12-1947$ & Lista Parcial n.17 & $08-03-1957$ \\
\hline Lista Parcial n.4* & $12-08-1950$ & Lista Parcial n.18 & $10-10-1957$ \\
\hline Lista Parcial n.6* & $04-01-1951$ & Lista Parcial n. 20* & $12-02-1959$ \\
\hline Lista Parcial n.7 & $22-08-1951$ & Lista Parcial n.23 & $30-07-1959$ \\
\hline Lista de 1948* & $11-01-1951$ & Lista Parcial n.25 & $23-11-1959$ \\
\hline Lista Parcial n. 8* & $13-08-1953$ & Lista Parcial n.26 & $28-12-1959$ \\
\hline Lista Parcial n. 9* & $13-08-1952$ & Lista Parcial n.27 & $01-01-1960$ \\
\hline Lista Parcial n. 10* & $23-03-1953$ & Lista Parcial n.31 & $24-03-1961$ \\
\hline
\end{tabular}

Tabela 1 - Listas localizadas

Observa-se que após a Lista Parcial Condicional n. 3 há uma interrupção na publicação. Este fato relaciona-se com o que foi anunciado pelo Ministro Clemente Mariani, em relação à alteração da legislação no que diz respeito à possibilidade de recurso por parte de editores e autores. Na referida entrevista da Folha da Manhã , ele considera que um ponto importante era "o da possível modificação da legislação vigente em relação ao livro didático". Segundo Mariani,

Estou solicitando à própria CNLD, à vista da experiência já obtida, sugestões a este respeito, para encaminhamento do assunto ao Legislativo.

A questão da possibilidade de recurso, da parte de autores que não obtenham para suas obras parecer favorável, por exemplo, deverá ser reexaminada. Pessoalmente, sou pela introdução de um dispositivo que permita o referido recurso, em determinadas condições (O LIVRO..., 1947, p. 2).

Esta consulta materializa-se na Portaria n. 44 de 3 de fevereiro de 1948, que suspende os efeitos da Portaria n. 363, de 31 de julho de 1947, que determinava a publicação das listas:

O Ministério de Educação e Saúde.

Considerando que, posteriormente a publicação da Portaria n. 363 de 31 de julho de 1947, opinou o Sr. Consultor Jurídico do Ministério no sentido da inexistência de recurso legal das decisões da Comissão Nacional do Livro Didático, consideradas aos interesses dos respectivos autores;

Tendo em vista que a inexistência desse recurso não se coaduna com o atual regime democrático, havendo a Comissão de Educação e Cultura, da Câmara dos Deputados, por solicitação do Ministério, apresentado um projeto em que é o mesmo instituído; e 
Atendendo a que esse projeto não chegou a ter a sua elaboração concluída, a tempo de serem resguardados os direitos dos que se julguem prejudicados pela decisão da Comissão Nacional do Livro Didático;

Resolve suspender a Portaria n. 363 até que, com a promulgação do projeto ora em andamento, no Congresso Nacional, possa ser-lhe dada execução.

Rio de Janeiro, 3 de fevereiro de 1948

Clemente Mariani (BRASIL, 1948).

Cabe observar que nem o Decreto-lei n. 1006 de 1938, nem o de n. 8460 de 1945, apresentavam itens relacionados com recursos por parte dos editores ou autores.

A divulgação das listas só é retomada após a publicação das normas que regularizaram os possíveis recursos. Isso ocorre por meio da Portaria n. 212, de 31 de maio de 1950. Segundo essa lei,

O Ministério de Estado, interino, de Educação e Saúde, atendendo ao que propôs a Comissão Nacional do Livro Didático, pelo Processo n. 33.13150, resolve expedir o seguinte Regulamento:

I - Das decisões das subcomissões especializadas ou comissões especiais haverá recurso para o Presidente da C.N.L.D. que o submeterá ao plenário, após informação prestada pela subcomissão especial que emitiu o respectivo parecer.

Parágrafo único. O recurso de que trata este artigo deverá ser devidamente fundamentado.

II - Das decisões da C.N.L.D. caberá ainda recurso para o Sr. Ministro da Educação e Saúde que decidirá, em última instância, ouvida uma comissão constituída, na forma do artigo 25 do Decreto-lei n. 8460, de 26 de dezembro de 1945.

III - Os recursos deverão ser julgados nos prazos máximos de noventa (90) dias, a partir de sua entrada na Secretaria da C.N.L.D.

IV - O direito ao recurso só poderá ser exercido pelo autor ou por quem, na forma da lei, possa representá-lo.

$\mathrm{V}-\mathrm{O}$ direito ao recurso prescreve no prazo de dois (2) anos, a partir da data em que foi emitido o parecer pela subcomissão especializada ou comissão especial.

VI - Contar-se-á o prazo de obrigatoriedade a que se refere o art. $3^{\circ}$ do Decreto-lei n. 8460 a partir do início do ano letivo de 1950. (BRASIL, 1950).

A partir de agosto de 1950 a publicação das listas é retomada, como pode ser observado na tabela apresentada anteriormente.

Quanto aos livros de matemática aprovados ou aprovados condicionalmente para uso na escola secundária, algumas análises podem ser feitas, mesmo sem considerar todos os detalhes contidos nas listas originais.

Figuram nas listas cerca de setenta e cinco autores, totalizando cento e cinco livros. Entre os autores, encontram-se alguns que são citados constantemente em pesquisa e, consequentemente, suas obras constam na base documental de trabalhos sobre livros didáticos de matemática no Brasil ${ }^{18}$. Por exemplo, Agrícola Bethlem, Algacir Munhoz Maeder, André Perez y Marin, Ary Quintella, Cecíl Thiré, Euclides Roxo, Isodoro Dumont e a Coleção F.T.D., Jácomo Stávale, Mello e Souza e Oswaldo Sangiorgi. Por outro lado, a lista revela diversos títulos, e os seus respectivos autores, que ainda não são citados na literatura especializada. Por exemplo, Alberto Alvares, Fernando Soares Rodrigues 
Vasconcelos, Frederico Carlos Spicacci, Justino Alves, Jonatas Dias Castro, Nelson Mariano Costa, entre outros. Nesse sentido, observa-se a circulação de livros didáticos de matemática no Brasil foi ainda maior. E, além disso, a análise dessas obras em sua materialidade fornece novos elementos para o campo de pesquisa. Como exemplo, podemos citar o livro de Alberto Alvares ${ }^{19}$, denominado Tratado de arithmetica, com segunda edição publicada pela Livraria Francisco Alves, em 1931. Nesta obra, os pareceres sobre a primeira edição, datada em 1907, estão presentes e mostram, por exemplo, as pessoas envolvidas na avaliação por parte do Conselho Superior de Instrução Pública de Minas e dados sobre a adoção e público de destino da obra. Neste caso, o ensino secundário das "Escolas Politécnicas, Liceus, Ginásios, Escolas Normais." (ALVARES, 1931, p. 5).

Outros títulos contidos nas listas mostram uma característica comum ao final do século XIX e início do XX, a saber, a circulação de obras portuguesas no Brasil. Por exemplo, três obras de José Adelino Serrasqueiro, autor indicado oficialmente no Colégio Pedro II nas décadas de 1890 e 1920 (BELTRAME, 2000), se encontram na lista, mostrando que esses textos ainda figuravam no cenário nacional de livros didáticos. Mas a presença de livros portugueses no mercado editorial brasileiro parece se revelar de maneira mais intensa. Nas listas foram localizados outros seis autores: Abel de Araújo Rego, Alberto Sá de Oliveira, Antônio Argel de Melo, Antônio Lobo Vilela, Diogo Pacheco de Amorim e Francisco Ferreira Neves ${ }^{20}$. É importante destacar que, nesse caso, para que o livro fosse avaliado o autor ou a editora deveria possuir representante no Brasil. Por exemplo, a Livraria Francisco Alves ${ }^{21}$ possuía livrarias-editoras na França e em Portugal, como por exemplo, a Biblioteca de Instrução Profissional (BRAGANÇA, 2004) ${ }^{22}$. Entre os autores portugueses citados, o último, Francisco Ferreira Neves, foi o obteve o maior número de obras aprovadas. No total, foram quatro aprovações: Álgebra e trigonometria, Elementos de aritmética racional para o VII ano dos Liceus, Elementos de geometria para $o$ I, II e III anos dos Liceus e Elementos de geometria para o IV, V e VI anos dos Liceus ${ }^{23}$.

A presença do autor José Adelino Serrasqueiro nos documentos da CNLD aponta também para outro fato importante, que é o grande número de edições de um título visto a presença de alguns deles nas listas de aprovados. Por exemplo, Noções de geometria prática, de Olavo Freire, em sua trigésima nona edição e Tratado Elementar de Aritmética do próprio Serrasqueiro, na vigésima terceira edição. Ambos os livros possuem primeira edição no século XIX.

Mas a avaliação e aprovação das obras destinadas a um dos ramos da matemática escola, como Serrasqueiro e Olavo Freire, vão além do fato de apontar um grande número de edições e sua aceitação no mercado brasileiro. A partir da década de 1930, ao menos oficialmente, a matemática escolar passou por uma mudança estrutural significativa. A separação dada a partir dos ramos (aritmética, álgebra e geometria, incluindo a trigonometria) é rompida com a fusão desses blocos, sob a denominação matemática. As reformas Francisco Campos (1932) e Gustavo Capanema (1942) instituíram e reafirmaram essa alteração em âmbito nacional ${ }^{24}$. No entanto, observa-se pelas listas que a produção e circulação de livros do tipo aritmética, álgebra e geometria e trigonometria permaneceram até pelo menos a década de 1950, visto, por exemplo, a Lista parcial n. 9, de 1952. Podemos citar, por exemplo, Elementos de álgebra, de André Perez y Marin; Lições de aritmética, de Euclides Roxo; Elementos de trigonometria, por F.I.C.; e cerca de seis títulos da coleção F.T.D., de Isidoro Dumont.

A autoria assumida nos livros da coleção F.T.D., citada acima, é outro fato que merece destaque na análise das listas. Como observado por Dalcin (2010), uma estratégia 
utilizada pelas ordens católicas era a omissão do nome do autor, pois dessa forma o coletivo seria valorizado e não a individualidade. Assim,

A prática de não divulgar a autoria era comum entre as congregações católicas [...]. As coleções F.I.C. e F.T.D., que tiveram uma grande penetração no ensino brasileiro, tanto em suas versões originais francesas como nas coleções adaptadas ao público escolar brasileiro, seguiam, na maior parte das vezes, essa prática. (DALCIN, 2010, p. 264)

A ausência do nome do autor na obra enviada para a CNLD era um dos critérios de exclusão listado no Decreto-lei n. 8460 do dia 26 de dezembro de 1945, mas que foi flexibilizado na execução da lei. Entre as publicações no Diário Oficial da União da Comissão Nacional do Livro Didático encontram-se os Despachos do Sr. Secretário. Em alguns deles, é requerido exigências que não foram cumpridas na abertura do processo de inscrição do livro. Entre elas, é possível observar o pedido de indicação do nome por extenso do autor, como determinava um dos itens de exclusão da obra presente na lei. Portanto, observa-se que o cumprimento da legislação então em vigor alterou a prática do anonimato na coleção de livros da F.T.D.. No caso dos livros da coleção F.I.C. não ocorreu uma alteração na impressão das obras. Eugênio de Barros Raja Gabaglia era mencionado como tradutor no texto impresso e como autor nas listas publicadas.

É possível observar também a partir dos livros de matemática contidos na lista a concepção de compêndios, dada pelo Decreto-lei n. 8460 de 26 de dezembro de 1945, como "livros que exponham, total ou parcialmente, a matéria das disciplinas constantes dos programas escolares" (Art. $2^{\circ}$ ). Com efeito, encontram-se na lista livros sobre tópicos específicos, como por exemplo, Lições de análise combinatória, de Francisco Antonio Lacaz Neto, produzidos para os Cursos complementares, instituídos na Reforma Francisco Campos. Além desses, dois merecem destaques como compêndios com exposições parciais, devido o pequeno recorte: Demonstrações práticas dos "Produtos notáveis", de Luigi Guiseppe Perperosa e Caderno para construções de sólidos geométricos, de Nelson Mariano Costa.

Além desse tipo de compêndio, encontram-se na lista, livros de exercícios, que em sua maioria não possuem exposição de conteúdo, mas foram enviados a CNLD e avaliados. Por exemplo, 1700 Exercícios de Álgebra, de Eduardo Celestino Rodrigues, com $3^{\mathrm{a}}$ edição publicada pela Editôra Clássico-Científica (RODRIGUES, s/d), "de acordo com os programas dos Cursos Ginasial e Colegial", contendo as respostas. Destaca-se também a coleção de Cecil Thiré denominada Manual de matemática, destinada às quatro séries do ciclo ginasial.

Outras observações podem ser feitas sem pormenores: os volumes, em caso de coleção, eram avaliados separadamente; duas tábuas de logaritmos constam como aprovadas (Manuel Faria e Marc Chollet); e, entre os autores brasileiros com mais de um título aprovado, destacam-se, Francisco Antonio Lacaz Neto, Jácomo Stávale e Nicanor Lemgruber.

\section{Considerações finais}

As dificuldades enfrentadas na execução da legislação sobre o livro didático no Brasil associadas à publicação das listas de livros aprovados ou aprovados condicionalmente foram, sem dúvida, a grande problemática na gestão de Gustavo Capanema. 
Rico na criação de normas, decretos, regulamentos e aditamentos de decretos, o período autoritário acaba muitas vezes privilegiando - pela própria lógica de seu funcionamento - decisões de gabinete, essencialmente burocráticas que em grande parte mostram-se ineficazes pela inadequação de todo esse aparato normativo às situações mais concretas. A defasagem entre a produção das normas e sua aplicação prática pode até conduzir ao aceleramento da criação de outros procedimentos legais para suprir a deficiência encontrada. Esse processo vai se perpetuando pela fecundidade com que se pretende responder normativamente a cada expectativa não cumprida (OLIVEIRA; GUIMARÃES; BOMÉNY, 1984, p. 45).

Consequentemente, o setor de editorial movimentou-se de forma intensa em relação a esta temática. As reinvindicações justificam-se, pois no período entre 1938 e 1943, como apresentado por Micelli (2001), os livros didáticos ocupavam o segundo lugar na produção de livros no país, considerando os diversos gêneros, como mostram as tabelas a seguir ${ }^{25}$ :

\begin{tabular}{|c|c|c|c|c|c|c|c|c|c|c|}
\hline $\begin{array}{l}\text { Empreendimentos } \\
\text { editoriais/Gêneros } \\
\quad \text { (9122 obras) }\end{array}$ & 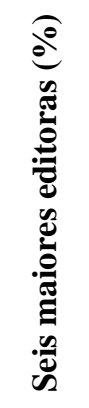 & 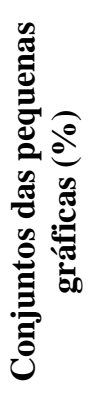 & 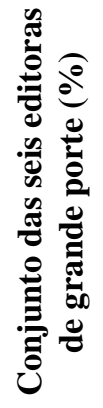 & 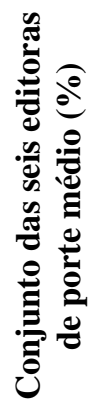 &  & 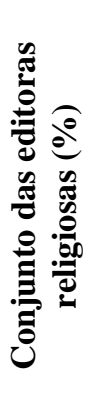 & 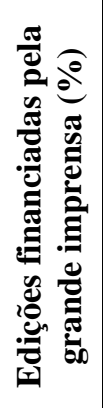 & 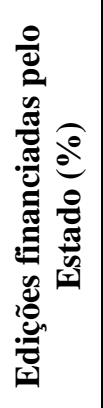 & 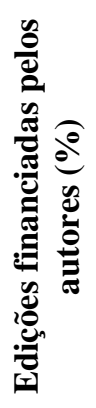 & 莺 \\
\hline $\begin{array}{c}\text { Ficção } \\
\text { (1527 obras) }\end{array}$ & 23,0 & 9,7 & 20,0 & 17,0 & 20,0 & 11,0 & 11,0 & 1,3 & 3,5 & 17,0 \\
\hline $\begin{array}{c}\text { Didáticos } \\
\text { (1240 obras) }\end{array}$ & 22,0 & 8,5 & 11,5 & 16,0 & 5,7 & 5,0 & 4,5 & 3,5 & 4,5 & 14,0 \\
\hline
\end{tabular}

Tabela 2 - A produção de livros segundo o gênero e as editoras (1938-43).

\begin{tabular}{|c|c|c|c|c|c|c|c|}
\hline $\begin{array}{c}\text { Seis maiores } \\
\text { editoras/Gêneros } \\
\text { (3239 de obras) }\end{array}$ & 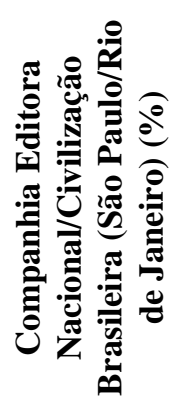 & 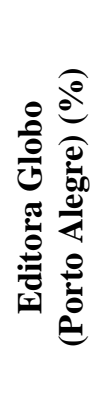 & 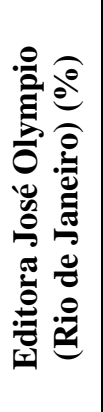 & 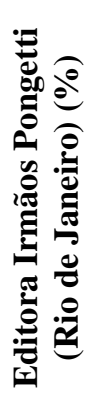 & 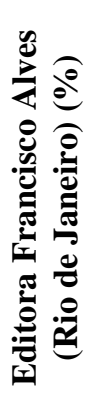 &  & 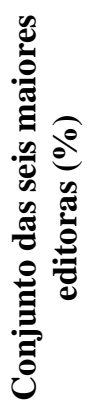 \\
\hline $\begin{array}{c}\text { Ficção } \\
\text { (748 obras) }\end{array}$ & 22,0 & 36,0 & 33,5 & 28,0 & 2,5 & 7,0 & 23,0 \\
\hline $\begin{array}{l}\text { Didáticos } \\
\text { (702 obras) }\end{array}$ & 26,0 & 11,0 & 1,5 & 4,0 & 65,0 & 28,0 & 22,0 \\
\hline
\end{tabular}

Tabela 3 - A produção das maiores editoras segundo o gênero (1938-1943). 
Como relatado por Micelli (2001),

As transformações do panorama editorial se devem, de outro lado [além da produção de literatura de ficção], às mudanças por que passava o sistema de ensino. A abertura das primeiras faculdades de educação, de filosofia, ciências e letras, a criação de novos cursos superiores, a reforma dos currículos, com a introdução de disciplinas recém-consolidadas, os impulsos que recebeu o ensino técnico e profissionalizante, decerto moldaram o ritmo e as feições que assumiu o surto editorial. A farta produção de obras pedagógicas acompanhou de perto os lances do enfrentamento entre as diversas correntes de educadores profissionais que buscavam firmar suas posições diante das reformas empreendidas pelo Estado (MICELLI, 2001, p. 155).

Observar-se, a partir de 1946, movimentos do poder central para discutir o processo de avaliação de livros didáticos e esforços para que a legislação fosse cumprida, mesmo tendo suas origens no período do Estado Novo, pois o Decreto-lei n. 8460, de 26 de dezembro de 1945, reafirmou claramente as intenções do Decreto-lei n. 1006, de 30 de dezembro de 1938. Mas é importante lembrar que a partir de 1946, sob a vigência da nova Carta Constitucional, os debates educacionais são intensos, principalmente, em função do projeto da Lei de Diretrizes e Bases da Educação, iniciado em 1948 e finalizado em 1961 com a promulgação dessa lei. Como observa Vieira (2007):

Os primeiros anos da redemocratização são agitados também no campo da educação, revelando elementos de contradição que expressam uma sintonia com o contexto político [...]. Pode-se dizer que o conceito de democracia limitada também se aplica às idéias pedagógicas que circulam no período. Assim, não é de estranhar a convivência entre tendências conservadoras e liberais, traço marcante do debate traduzido na Constituição de 1946 (VIEIRA, 2007, p. 300).

A partir do início da década de 1960, os debates sobre a politico do livro didático tomam outros rumos, como por exemplo, os altos preços desse tipo de impresso e a elaboração de livros didáticos por parte dos órgãos públicos ${ }^{26}$. Nesse momento, parece superada a ideia da existência de uma CNLD. Oliveira, Guimarães e Bomény (1984) transcreve parte de um parecer, datado em 1963, que expõe razões contra o Decreto-lei n. 8460 do dia 26 de dezembro de 1945 e, consequentemente, contra a CNLD ${ }^{27}$ :

"[...] o citado Decreto-lei consolidou uma longa série de atos legislativos e administrativos expedidos sob a vigência da Carta Constitucional de 1937 e inspirados no mesmo espírito centralizador que presidiu à elaboração da referida Carta. Esse elemento histórico faz prever, desde logo, que a Comissão Nacional do Livro Didático, criada em 1938 e retocada ano e ano segundo a orientação dominante, não poderia ajustarse à Constituição atual e menos ainda, à L.D.B., nascidas ambas sob o signo da descentralização" (ALMEIRA JÚNIOR et al. apud OLIVEIRA; GUIMAR ̃̂̃ES; BOMÉNY, 1984, p. 46).

Dessa forma, as ações federais em relação ao livro didático que buscaram o funcionamento da CNLD perpassam esse período, até que a consolidação dos ideais educacionais pudesse sanar a falta de "[...] um plano de conjunto que permitisse uma ordenação unificadora da educação nacional em seu todo [...]", em contraponto as reformas 
parciais (SAVIANI et al., 2006, p. 38). Cabe destacar que a CNLD foi extinta em 1969 pela Portaria Ministerial n. 594 de 27 de outubro do referido ano, entretanto, a partir de 1961 nenhuma lista foi encontrada.

Em relação às listas localizadas, acredita-se que tais fontes possam contribuir para as pesquisas sobre história das disciplinas escolares. Por exemplo, a seguir encontram-se todas as categorias/disciplinas apresentadas na divulgação das listas de livros e os respectivos níveis de ensino:

$\begin{array}{ll}\text { Ensino comercial: } & \text { história do Brasil, história da civilização, técnica comercial, história do } \\ & \text { comércio, francês, inglês, matemática, musica, direito, técnica industrial, } \\ & \text { contabilidade. } \\ \text { Ensino primário: } & \text { cartilha, leitura, matemática, história do Brasil, história da civilização, } \\ & \text { geografia, corografia, cosmografia, admissão. } \\ \text { Ensino secundário: } & \text { português, latim, inglês, francês, alemão, espanhol, grego, história do } \\ & \text { Brasil, história geral, história da civilização, geografia geral, geografia do } \\ & \text { Brasil, corografia, cosmografia, geofísica, filosofia, sociologia, religião, } \\ & \text { história natural, física, química, biologia, ciências físicas e naturais, } \\ & \text { higiene, matemática, desenho, instrução moral e cívica, metodologia das } \\ \text { técnicas, pedagogia, técnica escolar, música, dicionário, psicologia. }\end{array}$

Em relação aos livros de matemática destinados à escola secundária brasileira, futuras análises podem ser realizadas utilizando os dados completos das listas, encontrados nos documentos originais, ou a partir do cruzamento de fontes, como por exemplo, os pareceres que foram produzidos pela $\mathrm{CNLD}^{28}$. Por outro lado, algumas temáticas de investigação já se fazem presentes: os critérios estabelecidos em particular para a avaliação dos livros dessa disciplina; as editoras envolvidas no processo; a circulação e uso dos livros portugueses no Brasil; as alterações nos livros didáticos já aprovados em relação ao reajuste dos programas do ensino secundário em $1951^{29}$. Por fim, é importante salientar que as listas publicadas pela CNLD mostram que a produção de livros didáticos de matemática destinada à escola secundária no Brasil é significativamente ampla e envolve um grande número de obras avulsas em contraponto ao número das denominadas coleções.

\section{Fontes primárias}

ALVAREZ, A. Tratado de arithmetica. 2 ed. Rio de Janeiro: Livraria Francisco Alves, 1931.

BRASIL. Decreto-lei n. 1006, de 30 de dezembro de 1938. Estabelece as condições de produção, importação e utilização do livro didático.

Portaria Ministerial n. 253, de 24 de dezembro de 1940.

Decreto-lei n. 4.244, de 9 de abril de 1942. Lei orgânica do ensino secundário.

Decreto-lei n. 8460, de 26 de dezembro de 1945. Consolida a legislação sobre as condições de produção, importação e utilização do livro didático.

Portaria Ministerial n. 363, de 31 de setembro de 1947. Dispõe sôbre a aprovação de livros didáticos. 
Portaria Ministerial n. 44, de 03 de fevereiro de 1948. Suspende os efeitos da portaria número 363, de 31 de julho de 1947.

. Portaria Ministerial n. 212, de 31 de maio de 1950. Aprova regulamento de recurso.

. Portaria Ministerial n. 594, de 27 de outubro de 1969. Extingue a Comissão Nacional do Livro Didático.

NEVES, F.F. Elementos de aritmética racional: para o VII ano dos liceus. Lisboa: Livraria Sá da Costa Editora, s/d.

O LIVRO didático nas escolas primarias, secundarias, profissionais e normais. Folha da Manhã, 11-09-1947, Primeiro Caderno, p. 2.

RODRIGUES, E.C. 1700 Exercícios de Álgebra. 3 ed. São Paulo: Editôra ClássicoCientífica, s/d.

\section{Referências}

BITTENCOURT, C. Em foco: história, produção e memória do livro didático. Educação e Pesquisa. São Paulo, v. 30, n. 3. pp. 471-473, set./dez. 2004,.

BRAGANÇA, A. Francisco Alves, uma editora sesquicentenária (1854-2004). In XXVII INTERCOM 2004. São Paulo - SP: Intercom - Sociedade Brasileira de Estudos Interdisciplinares da Comunicação, 2004. v. 1.. Disponível em:< http://www.uff.br/lihed/images/anibal_livros/franciscoalves.pdf >. Acesso em 16 nov. 2011 .

DALCIN, A. O ensino de matemática entre 1885 e 1929 no Colégio Salesiano Liceu Coração de Jesus: "bons cristãos, honestos cidadãos". Bolema, vol. 23, n. 35A, p. 241-268, abril. 2010.

FILGUEIRAS, J.M. Os processos de avaliação de livros didáticos na comissão nacional do livro didático. Anais do XIX Encontro Regional de História: Poder, Violência e Exclusão. ANPUH/SP - USP. 08 a 12 de setembro de 2008. Cd-Rom. Disponível em:

<http://www.anpuhsp.org.br/downloads/CD\%20XIX/PDF/Autores\%20e\%20Artigos/ Juliana\%20Miranda\%20Filgueiras.pdf >. Acesso em mar. 2011.

FREITAG, B.; COSTA, W.F.; MOTTA, V.R. O estado da arte do livro didático no Brasil. Brasília: INEP/REDUC, 1987.

FREITAS, I. A historiografia escolar na Comissão Nacional do Livro Didático: pareceres de Jonathas Serrano (1938/1941). História \& Ensino, Londrina, v. 12, p. 141-156, ago. 2006.

MICELI, S. Intelectuais à brasileira. São Paulo: Companhia das Letras, 2001. 
OLIVEIRA, J.B.A.e; GUIMARÃES, S.D.P.; BOMÉNY, H.M.B. A política do livro didático. São Paulo: Summus; Campinas: Editora da Unicamp, 1984.

SAVIANNI, D. et al. O legado educacional do século XX no Brasil. 2 ed. Campinas, SP: Autores Associados, 2006. (Coleção Educação Contemporânea).

SOARES, F.S.; ROCHA, J.L. As políticas de avaliação do livro didático na Era Vargas: a Comissão Nacional do Livro Didático. ZETETIKE, Cempem, FE, Unicamp, v. 13, n. 24, p. 81-112, jul./dez. 2005.

VALENTE, W.R. (Org). Euclides Roxo e a modernização do ensino da matemática no Brasil. Brasília: Editora da Universidade de Brasília, 2004.

. A matemática do ginásio: livros didáticos e as reformas Campos e Capanema. CDROM, ago. 2005.

Osvaldo Sangiorgi: um professor moderno. São Paulo: Annablume; Brasília: CNPq; Osasco: GHEMAT, 2008.

. A matemática do colégio: livros didáticos para a história de uma disciplina. DVD, fev. 2011.

Disponível em:<http://www.unifesp.br/centros/ghemat/DVD_s/HISTORIA/inicio.html>. Acesso em 10 abri. 2011.

VIEIRA, S.L. A educação nas constituições brasileiras: texto e contexto. Revista Brasileira de Estudos Pedagógicos, Brasília, v. 88, n. 219, p. 291-309, maio/ago. 2007.

\section{Dissertações e Teses}

ALMEIRA, R.C.M. Abordagens do conceito de proporcionalidade em livros didáticos de matemática no Brasil do século XX. 2004. Dissertação (Mestrado em Educação) - Pontifícia Universidade Católica do Rio de Janeiro, Departamento de Educação, 2004.

BARONE, J. Livros didáticos de matemática da editora FTD no cenário brasileiro: as primeiras décadas do século XX. 2008. Tese (Doutorado em Educação) Universidade Estadual de Campinas, Faculdade de Educação, 2008.

BELTRAME, J. Os programas de ensino de matemática do Colégio Pedro II: 18371932. Rio de Janeiro, 2000. Dissertação (Mestrado em Matemática) - Departamento de Matemática, Pontifícia Universidade Católica do Rio de Janeiro, 2000.

DASSIE, B.A. A Matemática do curso secundário na Reforma Gustavo Capanema. 2001. Dissertação (Mestrado em Matemática) - Pontifícia Universidade Católica do Rio de Janeiro, Departamento de Matemática, 2001. 
Euclides Roxo e a constituição da educação matemática no Brasil. 2008. Tese (Doutorado em Educação) - Pontifícia Universidade Católica do Rio de Janeiro, Departamento de Matemática, 2008.

FERREIRA, R.C.C. A Comissão Nacional do Livro Didático durante o Estado Novo (1937- 1945). 2008. Dissertação (Mestrado em História) - Universidade Estadual Paulista, Faculdade de Ciências e Letras de Assis, 2008.

HELMER, H. Equações do segundo grau: métodos de resolução e análise em livros didáticos antes e durante o movimento da matemática moderna. 2005. Dissertação (Mestrado em Educação) - Universidade Federal do Espírito Santo, Vitória, 2005.

KILL, T.G. O estudo de funções à luz das reformas curriculares: reflexos em livrosdidáticos. 2004. Dissertação (Mestrado em Educação) - Universidade Federal do Espírito Santo, Vitória, 2004.

LONGEN, A. Livros didáticos de Algacyr Munhoz Maeder sob um olhar da Educação Matemática. 2007. Tese (Doutorado em Educação) - Universidade Federal do Paraná, 2007.

ROCHA, J.L. A Matemática do curso secundário na Reforma Francisco Campos. 2001. Rio de Janeiro, Dissertação (Mestrado em Matemática) - Pontifícia Universidade Católica do Rio de Janeiro, Departamento de Matemática, 2001.

VALENTE, W. R. Uma história da matemática escolar no Brasil (1730 - 1930). São Paulo, 1997. Tese (Doutorado em Educação) - Faculdade de Educação, Universidade de São Paulo, 1997.

Notas

\footnotetext{
${ }^{1}$ Professor Adjunto II da Faculdade de Educação da Universidade Federal Fluminense, Doutor em Educação e Mestre em Matemática pela Pontifícia Universidade Católica do Rio de Janeiro (PUC-Rio).

${ }^{2}$ Esse trabalho foi publicado posteriormente sob o título O livro didático em questão, pela Editora Cortez.

${ }^{3} \mathrm{GC}$ g 1938.01.06.

${ }^{4}$ Seção de Línguas e Literatura; Seção de Matemática e Desenho; Seção de Ciências Físicas e Naturais; Seção de Geografia; Seção de História; Seção de Filosofia, Sociologia e Pedagogia; Seção de Metodologia das Técnicas; Seção de Matérias do Ensino Primário; Seção de Redação (BRASIL, 1940).

${ }^{5}$ Brasil, 1942.

${ }^{6}$ Este trecho faz parte da exposição de motivos apresentada por Gustavo Capanema, e publicada no Diário Oficial da União em 24 de março de 1944. O decreto do referido projeto, Decreto-lei n. 6.339, de 11 de março de 1944, foi publicado em 15 do mês citado.

${ }^{7}$ Publicado no Diário Oficial da União no dia 28 de dezembro de 1945. A Folha da Manhã em $1^{\circ}$ de janeiro de 1946, publicou no Primeiro Caderno uma síntese desse decreto.

${ }^{8}$ Como foi relatado, a partir das pesquisas de Oliveira, Guimarães e Bomény (1984), Soares e Rocha (2005) e Ferreira (2008), a predeterminação de um marco provocou inúmeros questionamentos sobre a publicação das listas de livros.

${ }^{9}$ Raul Leitão da Cunha foi Ministro da Educação e Saúde entre outubro de 1945 e janeiro de 1946.

${ }^{10}$ Clemente Marini foi Ministro da Educação e Saúde entre dezembro de 1946 e maio de 1950.
} 
${ }^{11}$ Os trechos sobre a possibilidade de recuso por parte de autores e editores serão citado mais a frente.

12 Este reportagem foi localizada no acervo da Folha de São Paulo, disponível para consulta em http://acervo.folha.com.br.

${ }^{13}$ Publicada no dia 02 de agosto do mesmo ano.

${ }^{14}$ Não há regularidade na publicação das listas.

${ }^{15}$ Os dois últimos dígitos no número do processo, ao que tudo indica, referem-se ao ano que o livro foi apresentado a CNLD.

${ }^{16}$ A indicação para o preço foi feita a partir da lista de n. 14, inclusive.

${ }^{17}$ Algumas listas não foram localizadas se considerarmos a numeração dada. A marcação feita (*) ao lado de cada título indica a presença de livros de matemática destinados ao ensino secundário. A lista de número 15 foi realmente publicada após a lista 16 , como pode ser visto na tabela.

${ }^{18}$ Ver, por exemplo, Almeida (2004), Barone (2008), Dassie (2008), Helmer (2005), Kill (2004), Longen (2007); Valente (1997, 2005, 2008, 2011).

${ }^{19}$ O livro de Alberto Alvares é citado no Catálogo da Livraria Francisco Alves no ano de 1933, mas não foi encontrado nenhum trabalho que faça referência a esse livro. Esse catálogo se encontra em http://www.uff.br/lihed/.

20 Algumas das obras aprovadas foram localizadas no acervo da Biblioteca Nacional de Portugal. Por exemplo, Elementos de geometria analítica plana, de Alberto Sá de Oliveira, publicado pela Livraria Atlântica, Coimbra, em 1932; e Compêndio de aritmética racional: feito de harmonia com os programas de $6^{a}$ e $7^{a}$ classes dos liceus, de Diogo Pacheco de Amorim, pulicado pela Coimbra Editora, em 1931.

${ }^{21}$ Para maiores detalhes sobre a Livraria Francisco Alves e os livros escolares, ver Bragança (2004).

${ }^{22}$ Um título, por exemplo, que circulou no Brasil foi Aritmética prática (s/d). Esta coleção foi dirigida por Thomaz Borballo Pinheiro.

${ }^{23}$ Francisco Ferreira Neves é autor de outros três livros didáticos, como observado na lista contida em Neves (s/d, p. 5).

${ }^{24}$ Para maiores detalhes sobre essas reformas, ver Dassie (2001), Rocha (2001) e Valente (2004).

${ }^{25}$ Dados extraídos de Miceli (2001, p. 152-153).

${ }^{26}$ Ver, Oliveira, Guimarães e Bomény (1984, p. 47-52).

${ }^{27}$ Este parecer foi assinado por A. Almeida Júnior (relator), Abgar Renault, José Barreto Filho e Ajadil de Lemos (OLIVEIRA; GUIMARÃES; BOMÉNY, 1984, p. 46).

28 Por exemplo, Filgueiras (2008) localizou alguns pareceres no arquivo da Companhia Editora Nacional/IBEP e Freitas (2006) analisa os pareceres de Jonathas Serrano dos livros de História do Brasil e História da Civilização, submetidos no ano de 1941, localizados no Arquivo Nacional.

${ }^{29}$ Por exemplo, a coleção de Elementos de matemática, de Jácomo Stávale, elaborada para a Reforma Campos consta nas quatro primeiras listas (1947 e 1950) e suas edições após 1951 apresentam nota impressa sobre uso autorizado.

Recebido em janeiro/2012

Aprovado em junho/2012 